Original Research Paper

\title{
Storm Runoff Estimation Using an Object Oriented Approach Based on the Concepts of System Dynamics
}

\author{
${ }^{1}$ Maryam Ghashghaie, ${ }^{2}$ Saeid Eslamian, ${ }^{3}$ Kaveh Ostad-Ali-Askari and ${ }^{4}$ Ali Hasantabar Amiri \\ ${ }^{I}$ PhD of Water Resources Engineering, Department of Water Resources Engineering, \\ Faculty of Agriculture, Bu-Ali Sina University, Hamedan, 6517833131, Iran \\ ${ }^{2}$ Department of Water Engineering, Isfahan University of Technology, Isfahan, Iran \\ ${ }^{3}$ Department of Civil Engineering, Isfahan (Khorasgan) Branch, Islamic Azad University, Isfahan, Iran \\ ${ }^{4}$ Department of Civil Engineering, Lenjan Branch, Islamic Azad University, Lenjan, Isfahan, Iran
}

Article history

Received: 01-01-2018

Revised: 02-03-2018

Accepted: 17-03-2018

Corresponding Author:

Kaveh Ostad-Ali-Askari

Department of Civil

Engineering, Isfahan

(Khorasgan) Branch, Islamic

Azad University, Isfahan, Iran

Email: koa.askari@khuisf.ac.ir

\begin{abstract}
Developing nations are imposing the increasing impacts on their bio-resources due in part to their rising population, need to high economic growth and the incorporation of non-native technologies. Usually, watersheds are the major units, which are influenced leading to un-sustainability, specifically from the view point of water resources and hydrologic systems. Relying on a linear causal thinking, most of the hydrologic models fail to incorporate socioeconomic attributes of a watershed with its hydrologic and environmental ones. Based on a systems thinking philosophy, this paper aims to adopt an object-oriented approach based on the concepts of System Dynamics (SD) to analyze the dynamics in a hydrologic system in a watershed scale. This research focuses on a storm event and investigates the interaction between key elements of rainfall-runoff phenomenon. The paper adopts the concepts of SD such as stocks and flows to define objects in an OO-SD model. The results of the study show that this approach is capable of simulating rainfall runoff process and estimate the value of peak flow exactly. Also the model was compared with HEC-HMS and results showed that using Snyder method for HEC-HMS the exact value of peak flow is obtained for both events. The simplicity of the adopted methodology in this study doesn't limit the accuracy of runoff peak estimation.
\end{abstract}

Keywords: Rainfall-Runoff, Storm, Object Oriented, System Dynamics, HEC- HMS

\section{Introduction}

It has always been a big challenge to address the consequences of human activities on natural complicated systems. The problem will be more severe among developing nations due in part to their rising populations, developing economies and facing with new complexities.

Management of water resources is concerned with developing, controlling, regulating and beneficial application of water resources. In more details, management goals might be categorized in four major divisions: Improvement and development of water supply from water resources, protection and prevention of water pollution, make the best uses of water for recreational, navigation and hydroelectric power generation, reduction of damages due to drought and flood. To achieve these goals in water resources management, providing computational models is necessary. Different types of hydrologic models are in use, which can be classified in different categories based on their capabilities, complexity, scale, resolution and preciseness.

In scientists' and researchers' attitudes, mathematical models help to understand the real world phenomena thoroughly. Many of water specialists and decision makers agree with Wurbs (1994) that mathematical models play an important role to provide necessary quantitative information to make the best possible decisions in the real world of water management. Within these models, some are used in a watershed scale to accomplish the conversion of precipitation value to runoff discharge.

Watershed models are usually applied to convert the rainfall input to a runoff output. Furthermore, other 
elements and components (as secondary issues) are also taken into account when analyzing a system. Those models are also used to estimate the amount of water out flowing from the hydrologic units.

There are many physically based and conceptual modelling approaches which are used for simulating the rainfall-runoff processes (Pandey et al., 2008; Schuman et al., 2000; Anderson et al., 2002; Raclot and Albergel, 2006; Jang et al., 2007; Santhi et al., 2008). In addition, data mining technique like ANN has also been applied to forecast hydrologic and water quality responses of a watershed system (Minns and Hall, 1996; Sarangi et al., 2005).

Surface runoff plays an important role on soil erosion, nutrient loss of agricultural basins and water quality of the river (Burger et al., 2007). Using convenient hydrologic models is very important in determining the response of a basin to socio economic changes as well as environmental. In fact, they help to understand the hydrologic response and impacts of different management actions (Rao et al., 2000; Tripathi et al., 2003; Gosain and Rao, 2004; Arabi et al., 2008)

Many studies have been accomplished on the evaluation of a specific rainfall-runoff model for the simulation of runoff and soil loss using field-scale models such as USLE, CREAMS and GLEAMS, event-based watershed-scale models such as AGNPS and ANSWERS, continuous time step-lumped watershed models such as HSPF, SWRRB and SWMM and continuous time stepdistributed parameter models such as SWAT, WEPP, MIKE SHE, ANSWERS, TOPMODEL and HEC-HMS. Also some studies have focused on comparing two or more hydrologic models (Johnson et al., 2003; Kallin and Hantush, 2006; Nasr et al., 2007; Verma et al., 2010).

Hydrologic models could be categorized in different ways, from uncertainty degree it encompasses deterministic to stochastic models, in terms of resolution vary between lumped to distributed models, from the knowledge of variables relation aspect it is confined in black box and white box models (Moradkhani and Sorushian, 2009) and it is categorized into conceptual to empirical models from physical basis.

Briefly it could be expressed that in deterministic models, physical rules such as energy and mass balance construct the basis of modelling (Kalteh, 2007). Also black box models such as Artificial Neural Network (AAN) usually don't give much information on association and relation of variables and no understanding of mechanisms is learned by this type of modelling.

For the conceptual modelling in spite of deterministic modelling, physical rules are not demonstrated but representing credible basis of system under study is possible.

In lumped models, the spatial variation is not taken into account and parameters are assumed as a single value for a specified area and in the process the amount of discharge is estimated at the outlet of the basin.

Apart from above division, there are two main categories of watershed models consisting of: Single event and continuous models. Continuous models are grouped into two major classes including models, which take into account the quality of water and the models which do not consider the quality and only concentrate on water (runoff) quantity. A brief review of hydrologic models is presented as follows (Table 1).

Table 1: A brief review of some hydrologic models

\begin{tabular}{|c|c|}
\hline Model & Description \\
\hline HEC -1 & $\begin{array}{l}\text { A lumped parameter model, simulates the surface runoff for a single precipitation event, also a package } \\
\text { consisting of different computational methods, economic analysis of flood damage and optimizing flood } \\
\text { control system are enclosed in this package. }\end{array}$ \\
\hline HEC-HMS & $\begin{array}{l}\text { Benefits from OO modeling, also simulates the runoff inside a basin, each component of the system is } \\
\text { considered as an Object and its attributes are assigned and entered into that object. }\end{array}$ \\
\hline MIKE SHE & $\begin{array}{l}\text { A kind of fully distributed and integrated model; key processes of a hydrologic system such as precipitation, } \\
\text { snowmelt, canopy interception and evapotranspiration, overland flow, saturated zone flow and unsaturated } \\
\text { subsurface flow as well as channel flow are computed. }\end{array}$ \\
\hline SWMM & $\begin{array}{l}\text { A dynamic rainfall-runoff simulation model used for single event or long-term (continuous) simulation mainly } \\
\text { applied in urban areas, both for quantity and quality of water (Rossman, 2008). }\end{array}$ \\
\hline SWAT & $\begin{array}{l}\text { A continuous model with a physical basis, a useful tool to assess the impacts of management actions on } \\
\text { hydrology, water quality and sediment production on an ungagged watershed (Im et al., 2003) }\end{array}$ \\
\hline NFF & Estimates regional regression equations for estimating flood peak discharges. \\
\hline WMS & $\begin{array}{l}\text { A comprehensive graphical modeling environment for all phases of watershed hydrology and hydraulics, } \\
\text { consists of powerful tools to mechanize modeling processes such as automatically outlining the basin, } \\
\text { geometric parameter calculation, GIS overlay estimation ( } \mathrm{CN} \text {, rainfall depth, roughness coefficients). }\end{array}$ \\
\hline Rational Method & $\begin{array}{l}\text { One of the simplest and most popular methods of hydrology which computes peak discharge from an area } \\
\text { based on rainfall intensity and a runoff coefficient. }\end{array}$ \\
\hline GSSHA & $\begin{array}{l}\text { A distributed (two- dimensional) hydrologic model which is capable of analyzing surface runoff, channel } \\
\text { hydraulics, groundwater interaction, water quality and sediment transport. }\end{array}$ \\
\hline TR-20 & $\begin{array}{l}\text { Computes surface runoff caused by natural or synthetic rainstorm events, design complex watersheds, } \\
\text { composed of various sub-basins, river reaches and reservoirs. }\end{array}$ \\
\hline TR-55 & A simplified method to compute storm runoff in small, urbanized watersheds. \\
\hline
\end{tabular}


Though addressing different aspects of water resources problems, the prevalent hydrologic modelling approaches are seldom capable enough to take into account interactions among the components of a system under study. In addition, there are socio-economic mechanisms that influence hydrologic processes, which cannot be normally captured through the traditional engineering modelling tools due to their reliance on a linear thinking philosophy.

$\mathrm{SD}$ is a methodology, which is capable of considering all interactions between elements of a system. Software packages based on SD have been extensively used in the fields of simulating businesses, organizational systems, simple engineering and scientific systems. The SD models are built using three principal elements (stocks, flows and converters) and emphasizes on understanding the feedback structure of systems.

Introduced model in this study stems from a lumped conceptual modelling, which follows physical rules governing the principle of Rainfall to Runoff process. The aim of this study is not to introduce a model for comparing it with other existing methods' or applying it as a new method of estimating rainfall-runoff although this model could be outstretched and integrated more extensively taking into account more details and their relations from different sectors. At the same time, allowing for an open selection of different factors that affect the runoff magnitude such as socio economic issues, feedback effect of rainfall on watershed characteristics, land uses and vegetation is an advantage of such modelling procedure.

\section{Methodology and Study Area}

\section{The Study Area}

The study area is located in Mehran Basin in the southern part of Iran. Mehran River originates from Galedar plain and passing through Lamard, Bastak and Dejgan plains inflows to Persian Gulf. This study was accomplished at Dejgan station. The area of the basin is about $7370 \mathrm{Km}^{2}$ at Dezhgan station which is located at $55^{\circ} 16^{\prime} \mathrm{E}$ and $26^{\circ} 53^{\prime} \mathrm{N}$. Figure 1 shows the study area of the research.

\section{The Systemic Approach}

Water Resources problems are complicated due to their role in the society context, so a kind of tool is needed to be capable of dealing with complexities.

The SD modelling is one of the simulation techniques that could extend our findings of natural and water resources systems. This methodology allows the modeller to learn about the behaviour of the system through considering primary, major parts and principal relationships between different components of the system.

The knowledge of system analysis has shown to be more helpful since water resources problems have been becoming more and more complicated. This approach has been initiated since 1950, when a group of different specialists on various fields gathered together to solve their problem on water resources planning at Harvard University (Nandalal and Simonovic, 2003).

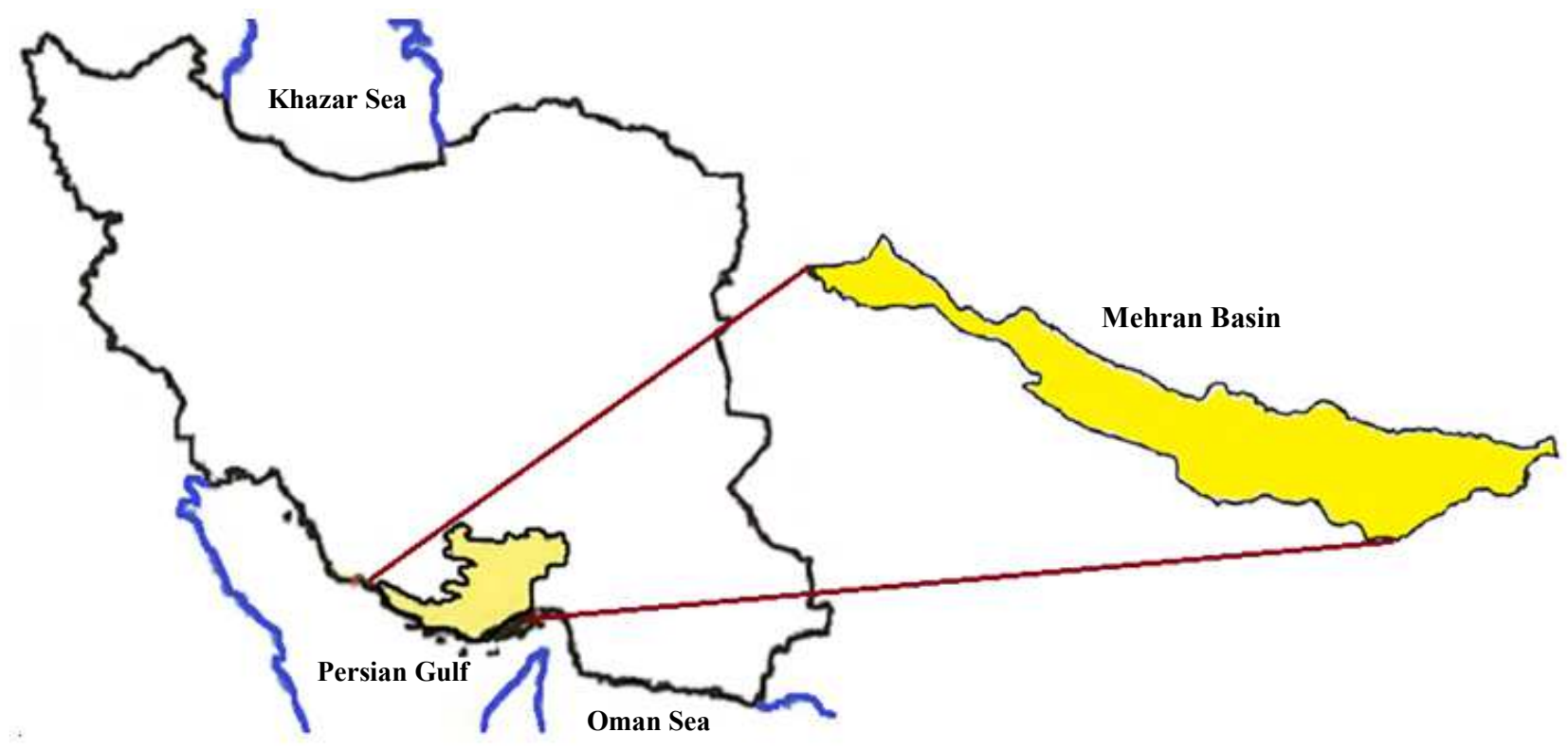

Fig. 1: The study area of Mehran Basin 
System dynamics have been successfully applied in many studies of water resources management. Dynamic simulation is a comprehensive approach, which is capable of producing real answers to the problems in spite of simplifications in presenting the components of a system. Using physical rules and relationships of phenomena is the reason for its success (Winz and Brierley, 2007). The domain of the SD application in water resources studies has been increased.

SD has been applied in integrated analysis of different scales such as regional (Connor et al., 2004; Cohen and Neale, 2006), national (Simonovic and Rajasekaram, 2004) and worldwide studies (Simonovic, $2002 \mathrm{a} ; 2002 \mathrm{~b})$. The application of SD in watershed management has been focused on water resources and their interactions with population growth (Van Den Belt, 2004; Gastelum Perez, 2006). The time scales of these studies and regional analysis models are 50 to 100 years. Also many works have been accomplished on flood management (Ahmad and Simonovic, 2004; 2006).

\section{The Methodology of Object Oriented (OO) Modelling}

The Methodology of Object Oriented (OO) modelling is a way of designing systems, whether they are natural or artificial. It is a way to organize data into discrete, recognizable entities called objects. These objects could be concrete (such as a river reach) or conceptual (such as a policy decision).

In every system to benefit this method, the first job is identifying different key elements and primary components of the system. In the OO methodology the systems are considered as a set of collaborative objects.

The objects capable of changing their states spontaneously are called Active Objects (Aboelata, 1998). According to this definition, each object is distinguished from the others by its properties. He categorized objects into three forms.

Actor is an object that can affect other objects but is never affected by any object, (in SD it is known as the external or exogenous variable). Server is an object that can never affect but is affected by other objects and finally agent which is an object that can affect and be affected by other objects, (the last two definitions correspond to the internal or indigenous variables in $\mathrm{SD})$. Each object sends its response function to the object in connection with through connectors.

The application of $\mathrm{OO}$ modelling requires some preliminary definitions of primary concepts such as class which is a package composed of many information variables. In a class, there are some functions, which use informative variables. These informative variables and functions are called information members and member functions respectively. When a class is used in a specific case it is known as an Object. A class is defined in an element construction.
Also a sub system model is a set of element models, e.g., in a sub basin scale reach and land uses are considered as two elements and a sub system is defined using these two kinds of elements. The whole model is composed of all sub systems which are connected and related to each other through clearly defined relations.

As many other modelling approaches, OO has an especial language for analysing and designing different systems and a modeller chooses a language to study and analyse one issue based on the problem under investigation and his/her preferences. The Unified Modelling Language (UML), programming languages such as FORTRAN, $\mathrm{C}^{++}$(Tisdale, 1996) and Java (Martinez et al., 2008) are within this category.

UML is used for the OO modelling. Indeed, it is a kind of graphical explanation for identification, realization and documentation of a system. Using the UML will help complex systems and their complicated processes to be more easily understood (Cantor, 1998).

Some models are also constructed based on programming languages such as FORTRAN, $\mathrm{C}^{++}$and Java. These are called procedure oriented languages. When objects and their attributes and relations are defined in a system dynamic context, Object Oriented modelling based on SD (OO-SD) will then be established. Besides all characteristics, which are possessed by different kinds of the OO modelling, a more understandable view of a system and interactions will be provided in this method.

$\mathrm{OO}$ is a powerful tool to model and analyse different natural and artificial systems such as water resources systems. It has been used since early 1990s. Also it has been applied as a basis of some hydrologic software such as HEC-HMS. In the very beginning application of this method, it was used to show the relation and association of system elements (Tisdale, 1996) then it was used in programming framework (Tisdale, 1996; Belkhouche et al., 1999; Wang et al., 2005; Martinez et al., 2008). System Dynamics is another suitable framework for OO modelling (Elshorbagy and Ormsbee, 2006).

This approach requires 3 kinds of diagrams to be constructed:

- The Class and Package diagrams consisting of different variables and functions. Functions, indeed, define the relation between variables of a class. They are also known as data members and member functions. Objects are recognizable when a class is used in case of a real component in a system and form a static state of the system

- A Dynamic Structure demonstrates the behaviours of different components in a system. These structures are known as sequential or collaborative diagrams (Ichikawa et al., 2000) 
- Finally a Functional structure which is the representation of objects variation over the time (Tisdale, 1996)

To construct any hydrologic model providing key elements would be necessary at first step. The sub system model is formed at the second step and finally the whole model is established and functioned.

\section{An Object Oriented Approach based on the System Dynamics Concepts}

Since hydrologic systems are generally considered to be interactively related in a watershed scale, an $\mathrm{OO}$ approach in combination with SD has been adopted to reflect the interactive dynamic nature of different attributes of each object in a system.

In the context of an OO-SD modelling, the key concepts within a basin, both physical and conceptual, are addressed as objects using stock and flow variables to represent them. The attributes of objects are also represented in terms of stock and flow variables as well.

Causal Loop Diagrams (CLDs) will be applied to visualize the causal relationships among the system objects and attributes. The CLDs also serve as effective means to enhance understanding of physical processes and dynamic mechanisms in the system under study. SD is a comprehensive methodology, which is capable of simulating the structure as well as the behaviour of a specific system.

As SD and OO have many joint concepts and principals they could be combined together effectively. Many definitions in a SD presentation of processes cover $\mathrm{OO}$ envisioning of problems. The easiness of the $\mathrm{OO}$ adaptation with SD help to find OO-SD an easily understood and attractive method.

Structure of a specific system, which is under study and ascertaining the relation between key parts of the system covers the Object Diagram of the OO Modelling. Using relevant software such as Vensim or Stella demonstrates the Dynamic and Functional Models of OO. At first stage of this work model tends to be satisfied in SD manner and the second stage obeys OO$\mathrm{SD}$ rules significantly.

The OO methodology has been introduced since 1990s; however, its different varieties have been being developed till now (Kiker and Clark, 2001). Although they are different in implementation, all of the methodologies are underpinned by a common main idea.

At first steps, it was initiated with the clear and accurate demonstration of systems and since then it has been grown up till now, more complicated subjects have been addressing using this method such as follow.

Tisdale (1996) represented the hydrologic systems of south Florida using an OO analysis. In this study, he clarified the objects and interactions of different components within the hydrologic system, though, no model was run.

Aboelata (1998) has introduced an OO modelling in his work. He has considered five water use sectors, consisting of agriculture, industry, domestic, navigation and power generation, in his model, which is a flexible planning tool for the Egypt's water resources system. Above mentioned sectors have been modelled separately and then were integrated into a single model. He has divided surface water into three classes: Rivers, lakes and control structures. Every class is divided into different divisions, e.g., for the case of surface water the other classes are introduced and the attributes of each class and the relations between different objects are defined.

Belkhouche et al. (1999) presented an OO water quality software system using $\mathrm{C}$ language programming. In their model, a framework was shown to develop a software system to analyse water quality of river ecosystems.

Using an OO design approach and the $\mathrm{C}^{++}$ programming language, Wang et al. (2005) defined the hydrologic processes in a watershed scale.

Elshorbagy and Ormsbee (2006) have applied an OO modelling in a system dynamic context to manage the water quality in Kentucky in the US. Martinez et al. (2008) applied an OO programming using java language to model shallow water table environments.

\section{Estimating Runoff based on OO-SD Modeling}

To show the capabilities and application of OO-SD in IWRM, a hydrologic model using OO-SD will be developed for analysing the rainfall-runoff mechanism. This modelling procedure aims to achieve the following objectives:

- Identification of major elements of the system

- Determining the classes and ascertaining the attributes of each class

- Instantiation (Tisdale, 1996) and clarifying the relationships between different objects

- Simulation of the process

In this illustration, the whole watershed is regarded as a system, which comprises of sub-basins as its subsystems and hydrologic processes such as rainfall, runoff, infiltration and evaporation. As other entities, objects are characterized with different attributes.

Components and elements of a system are embedded in a class structure. In a watershed system, there are crucial entities, which are active to convert the rainfall to runoff. In this illustration, the key components are chosen as objects represented by stocks and flows (Elshorbagy and Ormsbee, 2006). The classes in a watershed system can then be defined as: Sub basin, inflow of rainfall, outflow, infiltration and evaporation. 
To instantiate these classes and construct the objects of model, attributes of each class are assigned. In the present paper, the attributes of one object (sub basin) is allotted and for the other objects similarly, the inheritance rule will be applied. At the following steps the research focuses on elucidation of the main model, clarifying the object structure of a sub basin and finally illustrating its functionality using an example.

Water cycle or hydrologic cycle is a set of motions and cycling processes which occur in three different layers of the earth consisting of: Atmosphere, lithosphere and hydrosphere. Although water cycling forms a closed cycle considering the world as a whole, in a watershed it is not a closed system. Thus, to meet the principle of mass balance some part of the water flowing through a watershed should be considered as the basin storage volume $(I-O=\Delta S$, where $I$ and $O$ represent the inflow and outflow respectively and $\Delta S$ is the amount of water stored in the system). This principle underpins the hydrologic model introduced in this research.

\section{CLD of the Model}

To analyse the mass balance for the hydrologic system of a determined basin using $\mathrm{SD}$, it is essential to consider the system key elements, which are: Precipitation, runoff, evapotranspiration, interception, infiltration and surface retention inside the basin. Precipitation creates the total amount of water available on the surface of watershed; and the interaction between the existing surface water and the runoff makes a balancing loop. Moreover, the interaction between existing surface water and infiltration will create a balancing loop.

When the water capacity of soil is saturated, the infiltration rate will then remain at a constant discharge, that means the relative moisture percentage of soil and infiltration will create a balancing mechanism with a goal seeking behaviour.

Interception, on the other hand, causes a delay in the system, while it will finally lead in the system water loss through evaporation and infiltration. In this study, all types of water outflow in terms of evapotranspiration, interception and surface retention are aggregated into a single variable named as water loss.

In contrast to the prevalent models in hydrology, the adopted modelling scheme is capable of incorporating any other mechanisms and parameters and their feedbacks affecting the main process of hydrologic cycle through adding relevant sub-systems. That scheme is demonstrated in terms of a causal loop diagram in Fig. 2.

Analysing a water resources system whether in a sub basin or a watershed scale could be a challenging task without the help of SD and it is the capability of a SD methodology which allows for a clear, exact and easy designation of a system at the same time.

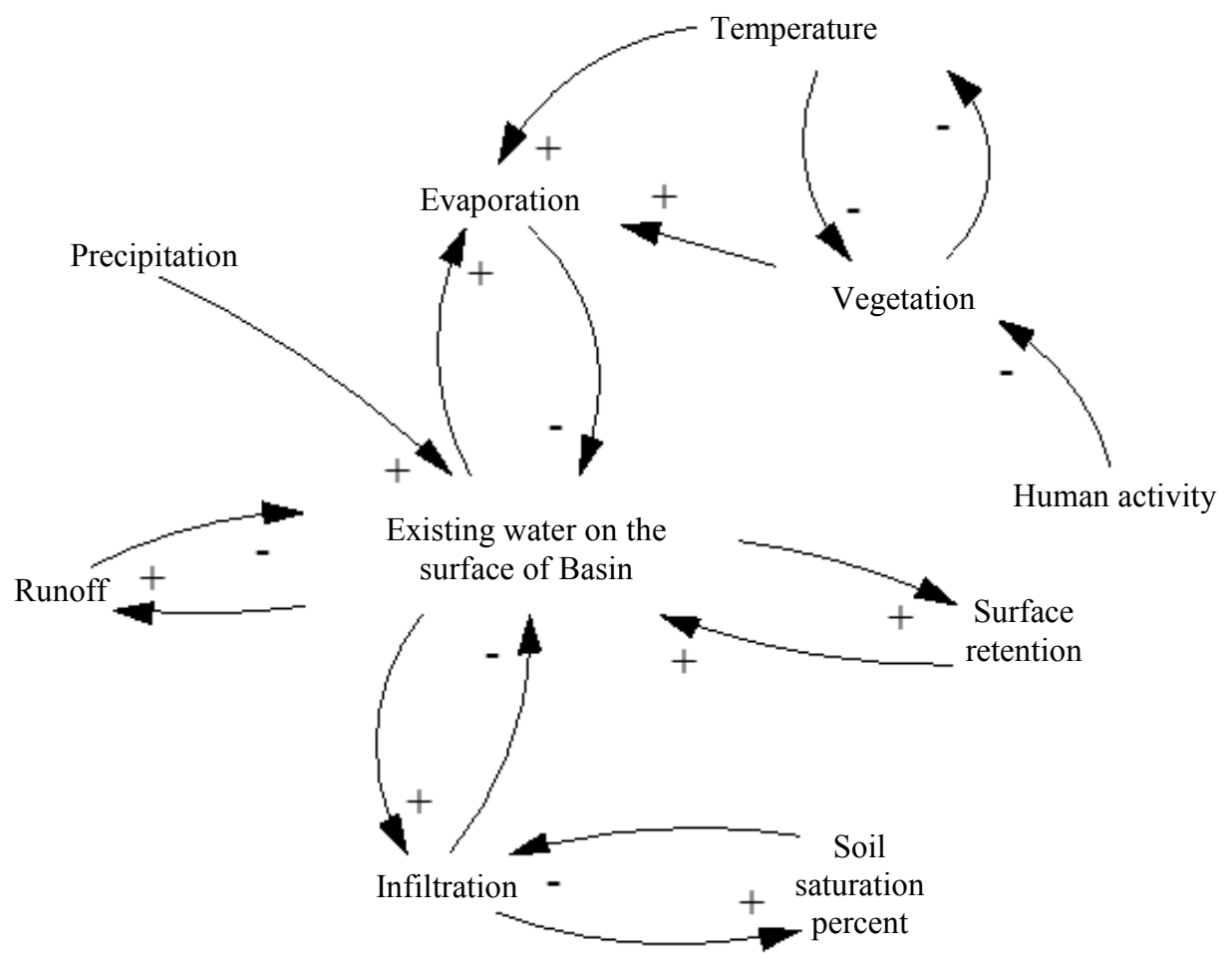

Fig. 2: The casual loop diagram of a sub basin hydrology 
As mentioned before rainfall-runoff process is studied in two major forms of single event and continuous. However, this research focuses on single events. Here, investigating the rainfall-runoff process is accomplished in two main stages. At the first phase the phenomenon is studied in a case of storm in which taking into account of essential processes happening simultaneously or after a lag time is of concern. These processes are including: Infiltration and evaporation phenomena perused in a single event rainfall-runoff model. Other kinds of losses are taken into account in rainfall losses such as: Interception and retention storage.

To test and examine the structure, behaviour and functionality of the model, it is run in VENSIM. The steps of model development for the first phase are explained in the following paragraphs.

Stocks and Flows define the classes composing the system and the relation between these classes is shown by equations. At First, different vital classes and their associations are introduced and then the objects, relations and behaviour of the system as a whole will be investigated for a case from Iran.

\section{Assumptions}

The obtained results are based on the premises made by a modeller. The assumption about this model are:

- No evaporation happens during the rainfall, so for the first case the amount of lag time for evaporation event is set 64 and for the second is considered to be $16 \mathrm{~h}$

- The amounts of final infiltration rate $=2 \mathrm{~mm} / \mathrm{h}$, porosity $=0.2$ and maximum water capacity of soil $=0.7$ is the same for both cases as they are in the same geographical location. Also the content of soil moisture is assumed the same for both events

\section{Model Construction}

The process of designing the model structure is presented in 5 stages:
- Here precipitation is the only source of water available in the basin and composes the runoff flowing into the bed river (Fig. 3). As it is shown any new module such as social, economic and political strategies can be added to the system. Indeed, these mechanisms affect the system behavior by altering the runoff (Fig. 3), infiltration (Fig. 6), or evaporation rate (Fig. 7).

- To calculate the runoff coefficient the volume of precipitation is required. A Co-Flow structure is used to estimate the runoff coefficient (Fig. 4)

- Runoff coefficient is calculated for each time step in this model. C is considered as an object which is a coefficient to determine the outflow from the existing water inside the Basin and is a time varying coefficient. The final amount of $\mathrm{C}$ clarifies the runoff coefficient. On the other side, the amount of runoff coefficient at each time step plays its role in calculating the evaporation coefficient for each time step, which will be explained later (Fig. 5)

- To calculate the infiltration rate, the amount of water entering the ground is determined according to the saturation condition of soil, as the amount of infiltration associates inversely with the saturation degree. This point is used to identify a lookup function for infiltration, which is a dependent variable of saturation degree. Soil porosity, maximum water capacity of soil and soil water content are the key factors in calculating the soil saturation degree (Fig. 6)

- The amount of evaporation is a fraction of existing water inside the basin which is estimated using runoff and infiltration coefficients (Fig. 7). The coefficient of evaporation is gained as Equation 1:

Evaporation Coefficient

$=1-C-$ Groundwater Coefficient

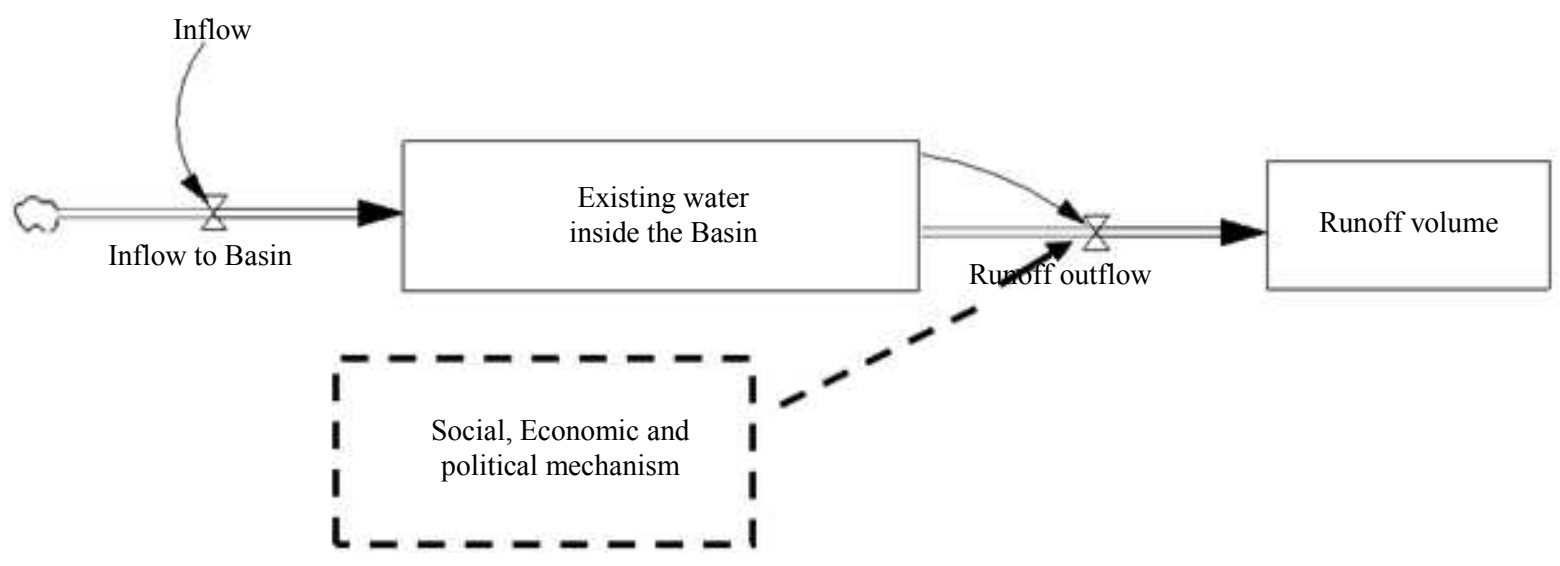

Fig. 3: The structure of rainfall-runoff and water volume 


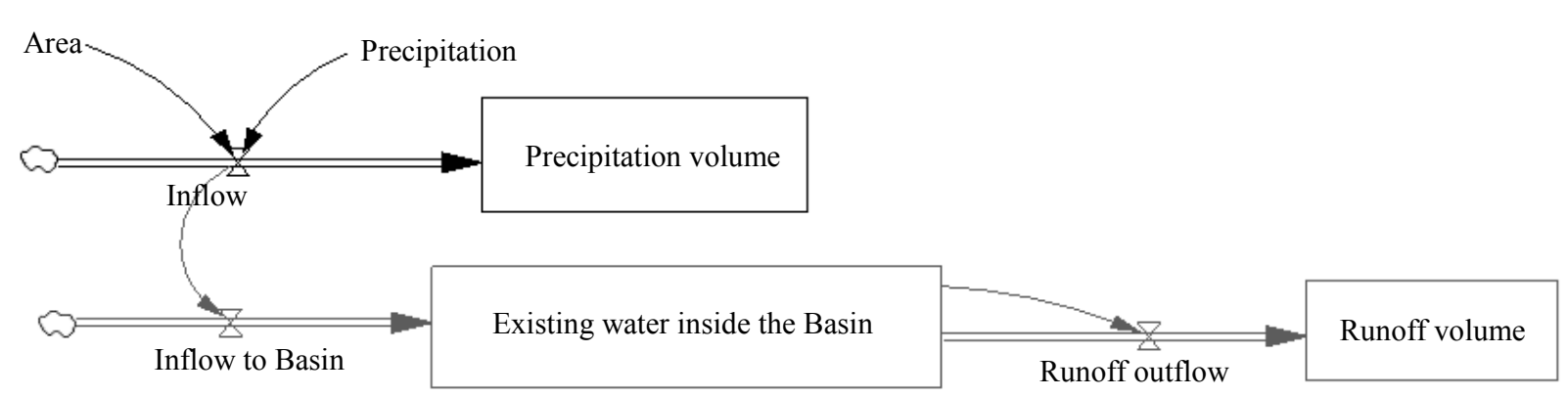

Fig. 4: The Co-Flow structure of precipitation and inflow to the basin

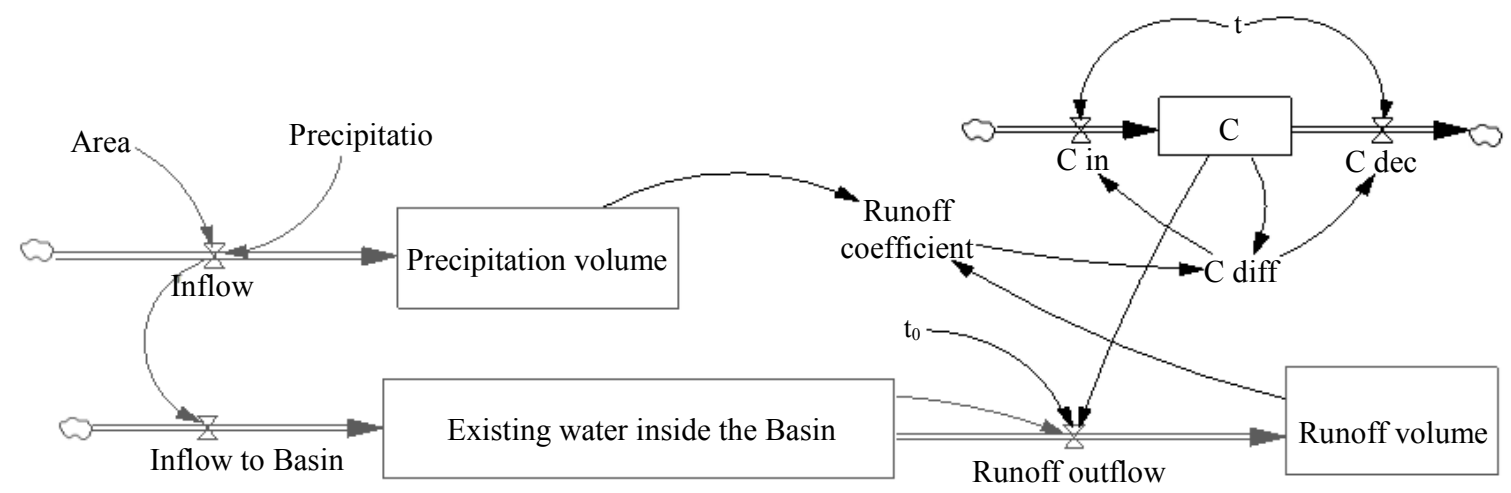

Fig. 5: Precipitation-runoff coefficient association

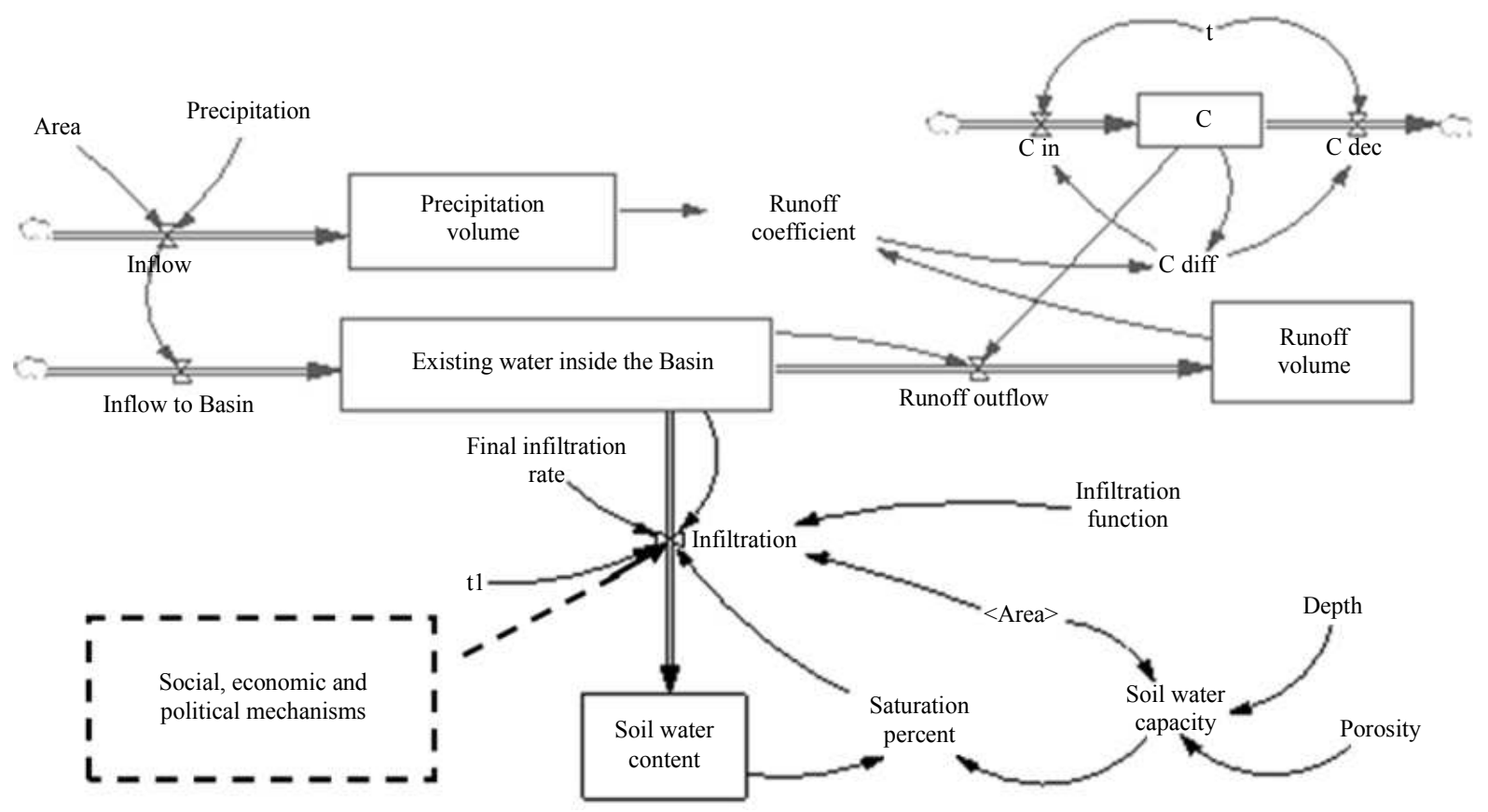

Fig. 6: Infiltration in a hydrologic system 


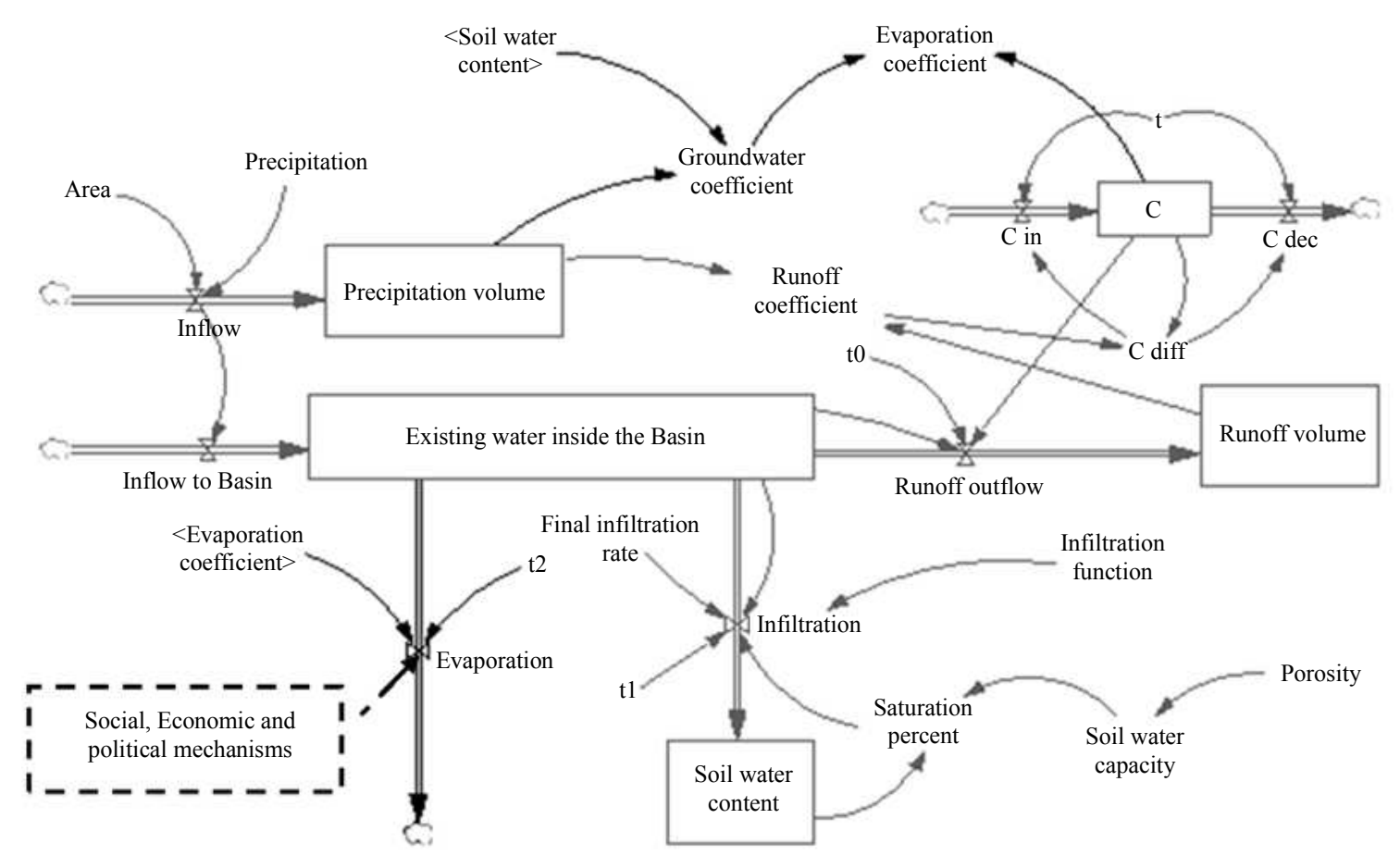

Fig. 7: A simplified exhibition of the class structure for a sub basin

In the past 5 steps, the classes of a sub basin system under investigation were presented to compose the whole structure of the system. Using the class structure of a sub basin for the Mehran River, the object structure of the problem under investigation will be established. The relationship between different classes is determined for the next steps.

Equation 2 shows the relationship between precipitation and existing water inside the basin:

Inflow $=$ Precipitation $\times$ Area $\left(\frac{m^{3}}{s}\right)$

where, precipitation is a time varying variable and is defined using a look up function of time. So, the accumulative and temporal volume of existing water inside the basin is calculated.

Also the relationship between runoff and existing water inside the basin is denoted in Equation 3:

Runoff Outflow $=C \times \frac{\text { Existing Waterinsidethe Basin }}{t_{0}}\left(\frac{m^{3}}{s}\right)$

where, $C$ is considered as a stock and is modified in each step by the following ratio:

$$
\left(\frac{\text { Runoff Volume }}{\text { Precipitation Volume }}\right)
$$

where, $t_{0}$ is the system delay time i.e., it shows the average time that takes the surface water to pass through the basin outlet.

A modeller needs to know how delays behave and choose among different types of delays in a stock-flow system. Delays are made when there is a lag between output and input time. A stock and flow diagram is used to show a material delay structure but it is important to find out the equation expressing outflow rate of material. Indeed, many elements outside the relation of stock and flow could affect the rate of outflow, so the length of delay and distribution of output around the average delay time are influenced by external factors. First In First Out (FIFO) and Last In First Out (LIFO) types of delay are two known delay definitions and other types of delays lay between these two forms (Sterman, 2000).

A hydrograph is a demonstration of water volume on surface of a basin at any specific interval of time, the discharge of which is specified at the outlet point of a basin. The volume of water inside the basin is accumulated in a stock. Considering only prismatic storage likewise a reservoir routing, no wedge storage is assumed. Using continuity rule by Equation 4, the stream outflows obeying type one delay which best matches the observed and estimated values of hydrograph:

$\frac{d s}{d t}=I-O$ 
Also for infiltration, a conditional statement was used considering the mechanism of infiltration, capillarity and gravity movement of water through the soil. Although the Green Ampt equation is a physical based equation, it is used when the rainfall is monotonous, thus, it has not been applied here. The equation used in the model is similar to that of Horton as follows Equation 5:

Infiltration $=\frac{\left(\begin{array}{l}\text { Final infiltration rate }+ \text { Infiltration } \\ \text { Function }(\text { saturation percentage }\end{array}\right)}{t_{1}}$

$\times$ Area,$\left(\frac{m m^{3}}{\text { hour }}\right)$

Also saturation percent is defined by Equation 6:

Saturation Percent

$=\frac{(\text { Soil Water Content }+ \text { Initial Soil Moisture })}{\text { Soil Water Capacity }},($ Dmnl $)$

Initial moisture, porosity and maximum saturation capacity of soil are important elements to achieve the amount of saturation percent, which can be written as Equation 7:

Saturation percentage

$=\frac{(\text { Soil Water Content }+ \text { Initial Soil Moisture })}{\text { Soil Water Capacity }},($ Dmnl $)$

And Equation 8:

Soil Water Capacity $=$ Porosity $\times$ Area $\times$

Depth $\times$ Soil Water Potential Capacity $\left(\mathrm{m}^{3}\right)$
The properties of soil are introduced as a lumped parameter in the model.

The evaporation coefficient is a complementary value for runoff and infiltration coefficients, its rate can be written as below Equation 9:

$$
\begin{aligned}
& \text { evaporation coefficient } \\
& \text { Evaporation }=\frac{\times \text { Existing } \text { water inside the basin }}{t_{2}},\left(\frac{m^{3}}{s}\right)
\end{aligned}
$$

Lag times $t_{0}, t_{1}$ and $t_{2}$ are considered for every 3 flows leaving the existing water inside the Basin. With respect to saturation condition of the air, delay time for evaporation is assumed equal to the rainfall duration time because during this time the air is supposed to be saturated and the rate of evaporation is considered to be zero.

In the following section, the model is run for a case example in Mehran River in the southern Iran, in Hormozgan Province.

\section{Calibration of the Model}

To calibrate the model two sets of observed rainfall-runoff data for two different storm events, from Dejgan station on Mehran River were used. Calibration of the model parameters was carried on $t_{0}$, $t_{1}$ and $t_{2}$, final infiltration rate, porosity and maximum water capacity were achieved for best results of both peak value of runoff and runoff volume. For instance, the amount of $t_{0}$ is 1 hour, $t_{1}=1 \mathrm{~h}, t_{2}=64 \mathrm{~h}$, final infiltration rate $=2 \mathrm{~mm} / \mathrm{h}$, porosity $=0.2$ and maximum water capacity of soil $=0.7$.

The observed and estimated runoff hydrographs are shown in Fig. 8.

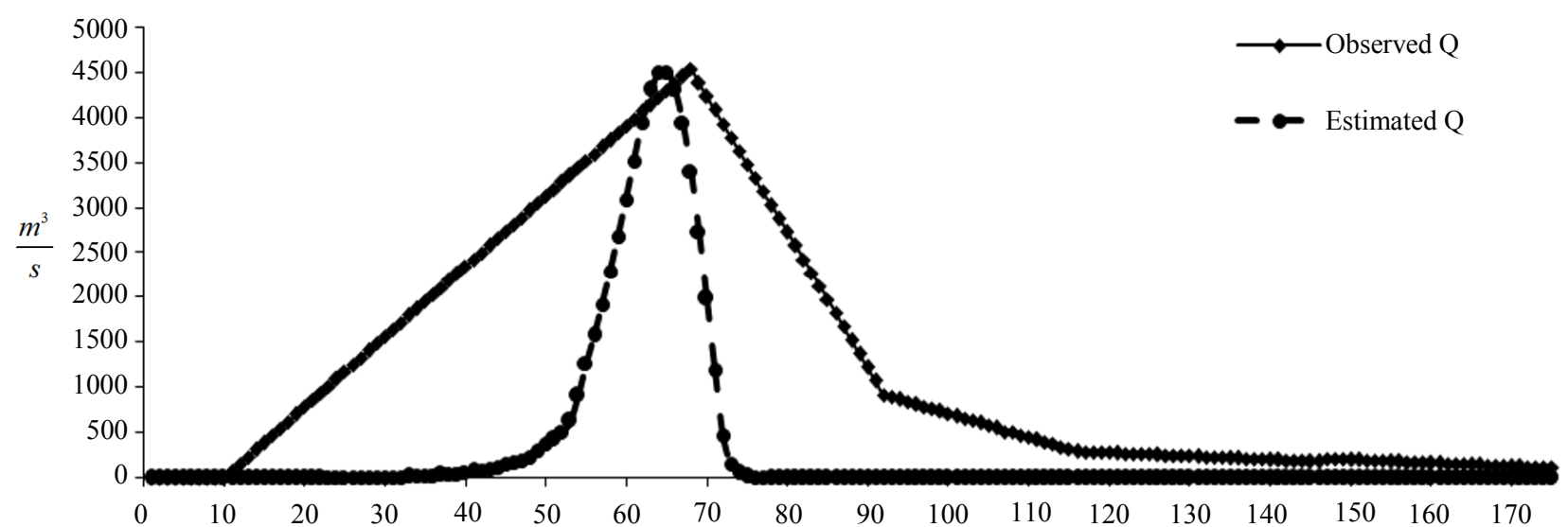

Fig. 8: Estimated and observed runoff hydrographs of the first event 


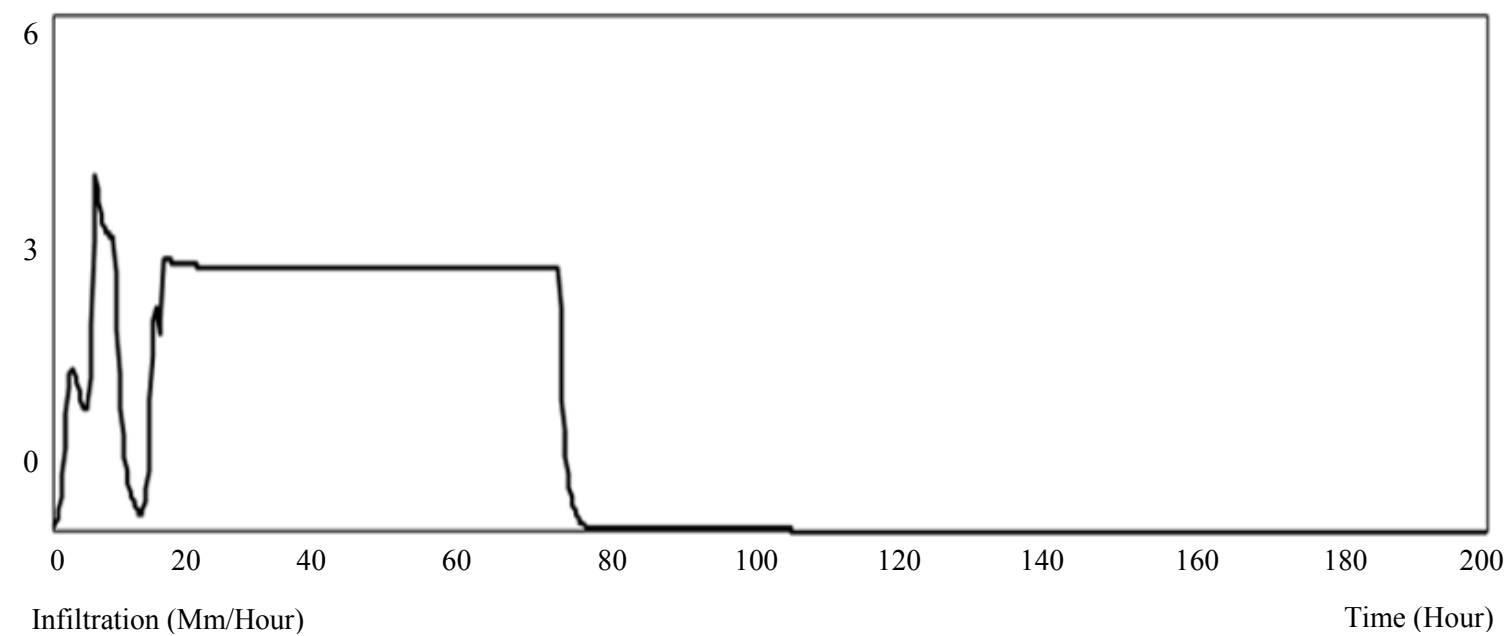

Fig. 9: Infiltration amount of the first event

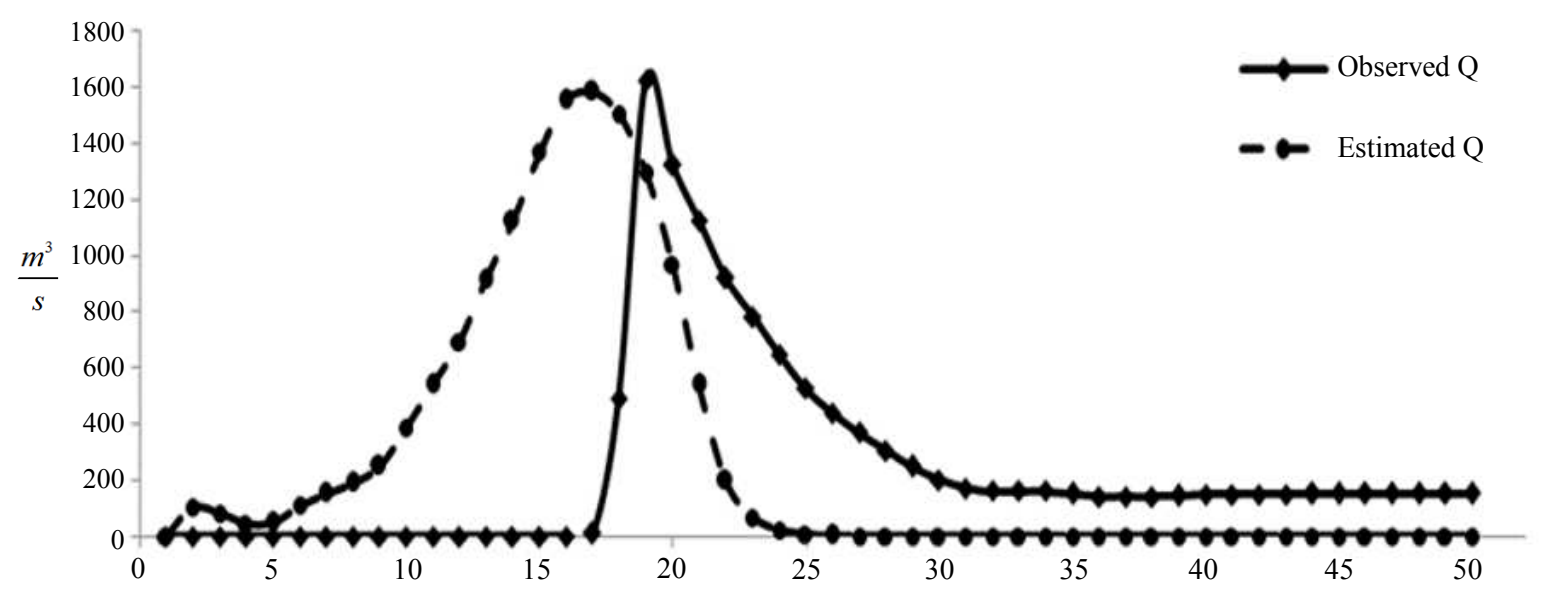

Fig. 10: Estimated and observed runoff hydrographs of the second event

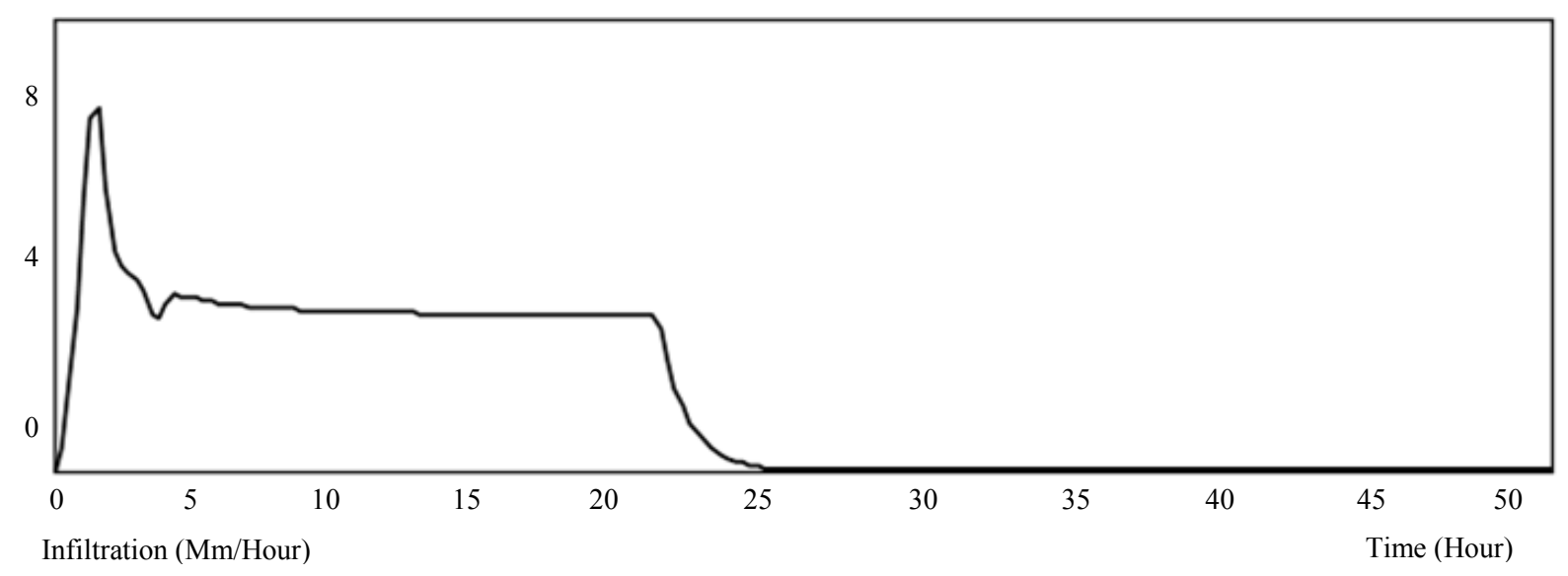

Fig. 11: Infiltration amount of the second event

Moreover, the rate of infiltration was achieved as demonstrated in Fig. 9. It is shown that the variation of infiltration during the time follows the general pattern of water infiltration through the soil. 
Also the model was run for another set of rainfall values and the results from the second run are illustrated in Fig. 10 and 11 for runoff and infiltration values.

The value of $t_{1}$ is 1 hour for the second data, $t_{2}$ is 16 hours and other parameters of the model such as infiltration rate, porosity and maximum water capacity of soil are the same as the first event. Indeed, they don't change as they show soil properties and the condition before the rain is assumed to be equal for both events.

\section{Results}

The value of peak flow estimated by the model follows the same as that of the observed data. Also the amount of runoff observed volume is $110 \mathrm{MCM}$, while that of achieved by the model is 203 MCM. Base time of estimated hydrograph is $82 \mathrm{~h}$, counting base flow and it is $256 \mathrm{~h}$ for the first event.

Likewise, for the second event, peak value of estimated runoff follows the maximum amount of observed runoff and the value of estimated runoff volume is gained 50.8 MCM which is near to that of observed volume, 48.6 MCM. Base time of estimated hydrograph is $38 \mathrm{~h}$, counting base flow and it equals to $60 \mathrm{~h}$ for the second event.

The simulation of the mentioned storms was also accomplished using HEC-HMS, which benefits from the OO modelling. HEC-HMS is a hydrologic modelling software developed by the US Army Corps of Engineers Hydrologic Engineering Center (HEC). It was developed to simulate the precipitation-runoff processes of various watershed systems such as large river basins, small urban and natural watersheds. The description of model structures and different processes are explained in the Technical Reference Manual (USACE-HEC, 2000) and the User's Manual (USACE-HEC, 2008) of HEC- HMS.

At first the problem was solved using Clark transformation method. Snyder transformation method was used at the second stage for both events. SCS curve number method was used for both stages. The results of parameters optimization for the first event are shown in Table 2.

Within different methods of optimization in HECHMS, Percent error in peak flow showed the nearest amount of estimated peak flow to the observed one, which is demonstrated in Table 3.

Figure 12 shows the comparison of observed and simulated outflow hydrographs.

Also the results of parameters optimization for the second event are demonstrated in Table 4.

Percent error in peak flow method was used for optimizing the parameters of model which showed the least difference between the observed and simulated values of discharge. The results of optimization for Clark unit hydrograph and sub basin $\mathrm{CN}$ is shown in Table 5.

Table 2: Ultimate parameters value of unit hydrograph and CN for the first event (Clark method)

\begin{tabular}{lllll}
\hline Element & Subbasin-1 & Subbasin-1 & Subbasin-1 & Subbasin-1 \\
Parameter & Clark Storage coefficient & Clark Time of Concentration & Curve Number & Initial Abstraction \\
\hline Units & HR & HR & - & MM \\
Initial Value & 10.00 & 20.00 & 80.00 & 10.00 \\
Optimized Value & 11.76 & 13.46 & 70.33 & 10.05 \\
Objective Function Sensitivity & 0.00 & 0.00 & 6.41 & 0.00 \\
\hline
\end{tabular}

Table 3: Comparison of observed and simulated peak flow for the first event (Clark method)

\begin{tabular}{lcc}
\hline Measure & Volume $(\mathrm{MM})$ & Peak Flow $\left(\mathrm{m}^{3} / \mathrm{s}\right)$ \\
\hline Simulated & 24.69 & 2425.5 \\
Observed & 6.58 & 1620.0 \\
Difference & 18.10 & 805.5 \\
Percent Difference & 275.03 & 49.7 \\
\hline
\end{tabular}

Table 4: Ultimate parameters value of unit hydrograph and CN for the second event (Clark method)

\begin{tabular}{lllll}
\hline Element & Subbasin-1 & Subbasin-1 & Subbasin-1 & Subbasin-1 \\
Parameter & Clark storage coefficient & Clark time of concentration & Curve number & \begin{tabular}{l} 
Initial abstraction \\
\hline Units
\end{tabular} \\
Initial Value & HR & HR & - & MM \\
Optimized Value & 20 & 80 & 14.25 \\
Objective Function Sensitivity & 0.0 & 10.118 & 80.118 & - \\
\hline
\end{tabular}

Table 5: Comparison of observed and simulated peak flow for the second event (Clark method)

\begin{tabular}{lcc}
\hline Measure & Volume $(\mathrm{MM})$ & Peak Flow $\left(\mathrm{m}^{3} / \mathrm{s}\right)$ \\
\hline Simulated & 125.83 & 5945.0 \\
Observed & 111.38 & 4526.0 \\
Difference & 14.44 & 1419.0 \\
Percent Difference & 12.97 & 31.4 \\
\hline
\end{tabular}




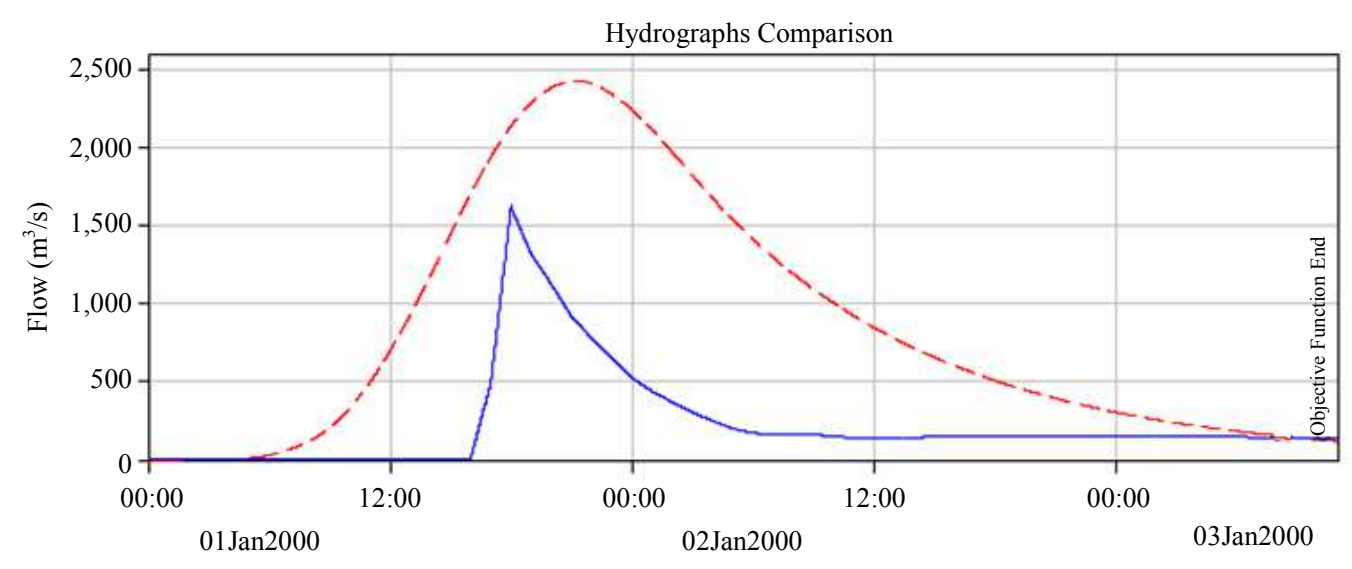

--- Subbasin-1 flow - Flow-observed

Fig.12: Comparison of observed and simulated hydrographs for the first event (Clark method)

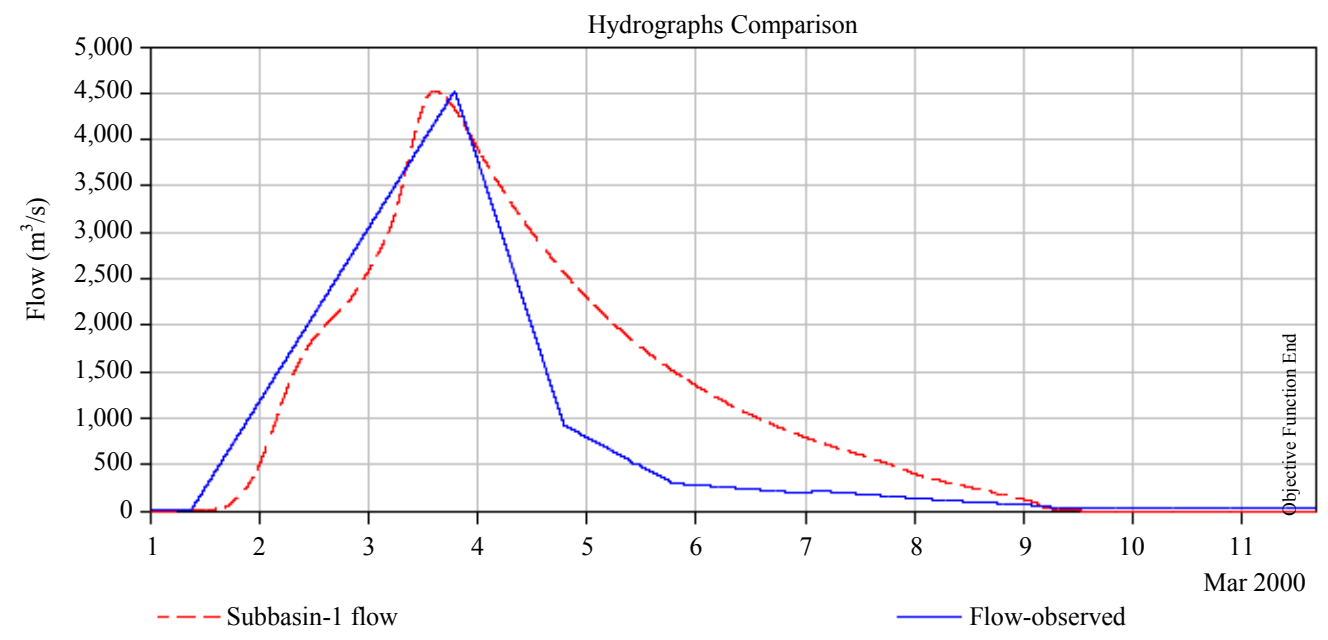

Fig. 13: Comparison of observed and simulated hydrograph for the second event (Clark method)

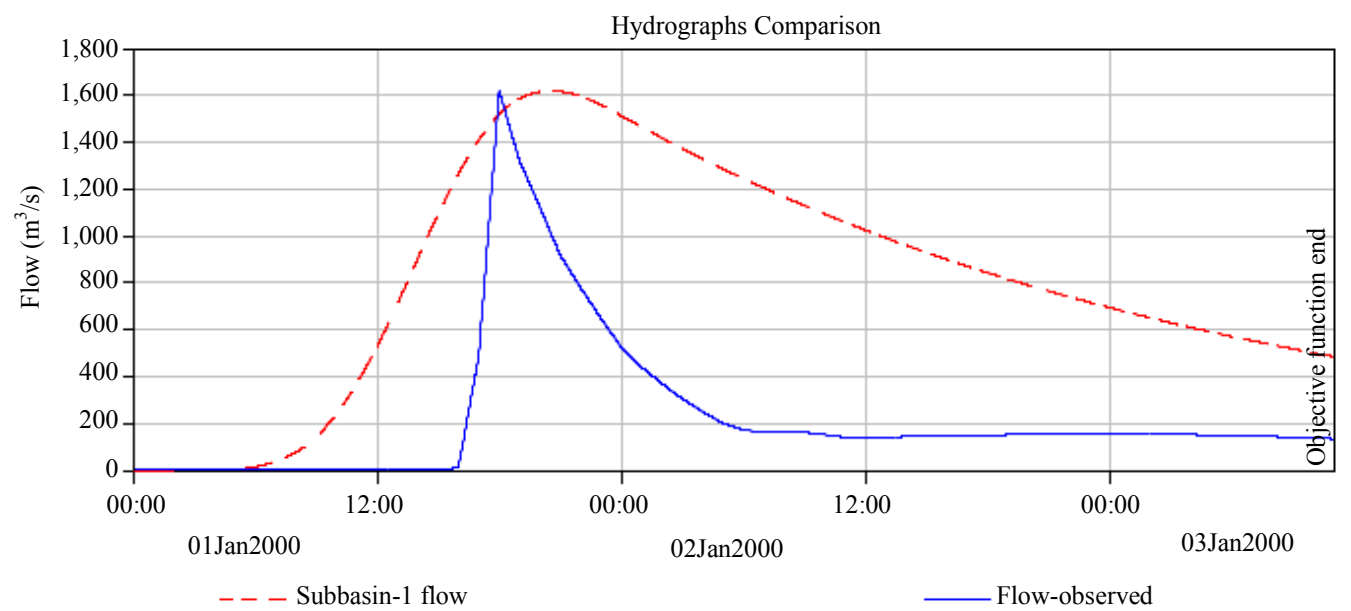

Fig. 14: Comparison of observed and simulated hydrograph for the first event (Snyder method) 
Figure 13 shows the comparison of observed and simulated hydrographs for the second event using Clark method.

Also model was run to obtain optimized values of Snyder unit hydrograph. Percent error in peak flow method was used for optimizing the parameters of model. It showed the least difference between the observed and simulated values of discharge for Snyder method.

The result show that using Snyder method simulated and observed hydrographs are more compatible for the first event as it is clear in Table 6 and Fig. 14.

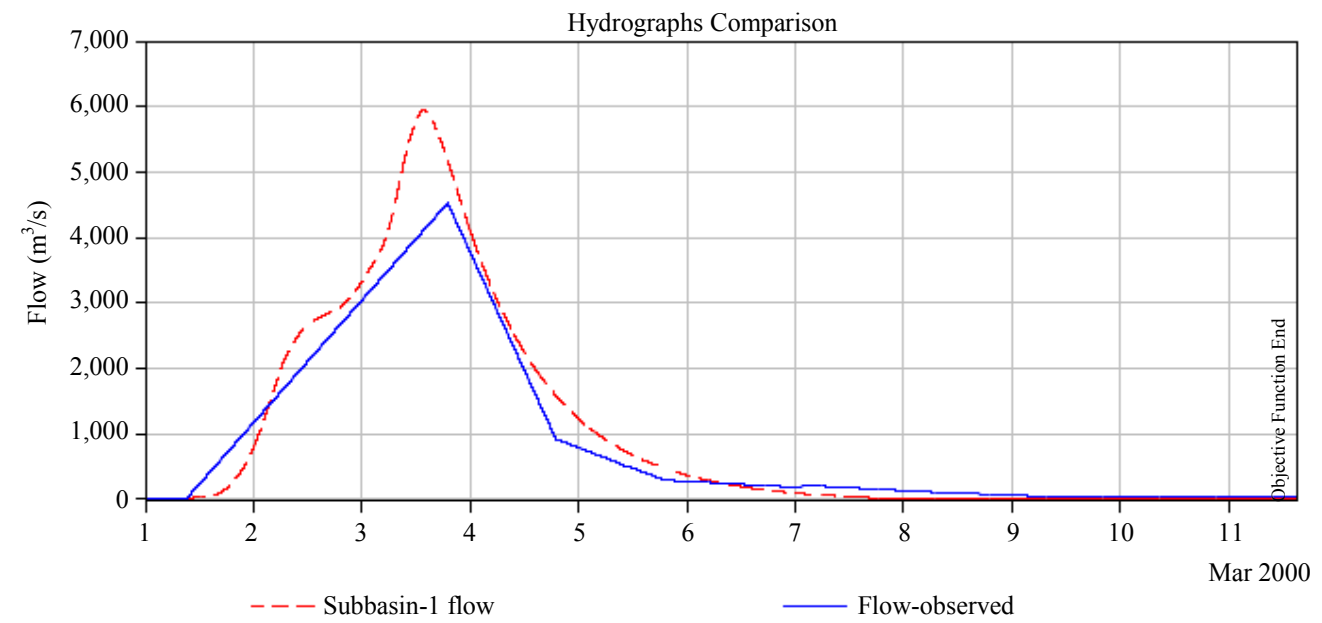

Fig. 15: The Comparison of observed and simulated hydrograph for the second event (Snyder method)

Table 6: The values of observed and simulated discharge for the first event (Snyder method)

\begin{tabular}{lcr}
\hline Measure & Volume $(\mathrm{MM})$ & Peak Flow $\left(\mathrm{m}^{3} / \mathrm{s}\right)$ \\
\hline Simulated & 23.84 & 1620.0 \\
Observed & 6.58 & 1620.0 \\
Difference & 17.26 & 0.0 \\
Percent Difference & 262.24 & 0.0 \\
\hline
\end{tabular}

Table 7: The optimized value for CN and Snyder unit hydrograph for the first event (Snyder method)

\begin{tabular}{lllll}
\hline Element & $\begin{array}{l}\text { Subbasin-1 } \\
\text { Curve Number }\end{array}$ & $\begin{array}{l}\text { Subbasin-1 } \\
\text { Initial Abstraction }\end{array}$ & $\begin{array}{l}\text { Subbasin-1 } \\
\text { Snyder Peaking Coefficient }\end{array}$ & $\begin{array}{l}\text { Subbasin-1 } \\
\text { Snyder Time to Peak }\end{array}$ \\
\hline Units & - & MM & - & HR \\
Initial Value & 80.000 & 14.25 & 0.300 & 10.000 \\
Optimized Value & 70.627 & - & 0.201 & 10.047 \\
Objective Function Sensitivity & 16.300 & - & 0.000 & 0.000 \\
\hline
\end{tabular}

Table 8: The values of observed and simulated discharge for the second event (Snyder method)

\begin{tabular}{lcr}
\hline Measure & Volume $(\mathrm{MM})$ & Peak Flow $\left(\mathrm{m}^{3} / \mathrm{s}\right)$ \\
\hline Simulated & 145.18 & 4524.3 \\
Observed & 111.40 & 4526.0 \\
Difference & 33.79 & -1.7 \\
Percent Difference & 30.33 & 0.0 \\
\hline
\end{tabular}

Table 9: The results of optimization for two events using HEC-HMS

\begin{tabular}{llrrrr}
\hline Run & & 1 & 2 & 3 & \multicolumn{1}{c}{4} \\
\hline CN & & 70.34 & 80.12 & 80.00 & 70.62 \\
CLARK UH & $\mathrm{T}_{\mathrm{c}}$ & 13.47 & 10.12 & & \\
& Storage Coefficient & 11.70 & 20.47 & 10.19 & 10.05 \\
SYNDER UH & $\mathrm{T}_{\mathrm{p}}$ & & & 0.28 & 0.20 \\
& Peaking Coefficient & & & 1620.00 & 4526.00 \\
Q peak & Observed & 1620.00 & 4526.00 & 1620.00 & 4524.30 \\
& Simulated & 2425.50 & 5945.00 & & \\
\hline
\end{tabular}


Table 7 shows the optimized values for $\mathrm{CN}$ and Snyder unit hydrograph

Also the results for the second event are demonstrated in Table 8 and Fig. 15 respectively.

Finally, Table 9 shows the results for both methods of Clark and Snyder unit hydrograph.

\section{Conclusion and Discussion}

The purpose of presenting such a model is not comparing its capabilities with other programs and environments capable of computing runoff from rainfall events. However, it is intended to introduce a dynamic paradigm of hydrologic modelling capable of incorporation of feedback mechanisms, which can be applicable in integrated watershed management. Besides with the rapid evolution of human ability to change the environment to get the most benefits, this kind of modelling always seems to be as an open model due to its flexibility. In addition, the sufficiency of required data has always been a matter of issue for other computer models to predict the outcomes of different situations. OO-SD allows for direct awareness of different human activities impacts on nature and will provide a platform to design strategies to manage the consequences of such improvident behavior of human beings. The results of changing the land use from agriculture to industry, deforestation affects the vegetation after more or less than 1 year, which can be considered when allotting a delay time for such a situation. The aim of this research was only to verify and demonstrate the capability of an OO-SD approach as a suitable methodology to investigate different strategies and select appropriate decisions by adding any artificial modules as a result of anthropogenic changes in nature. Based on the results of model run for two events, the adopted methodology demonstrates a capable methodology to construct runoff estimation model through which the exact value of peak flow is obtained. Also the comparison of model with a reliable software package like HEC -HMS supports that this model is quite good at estimating the runoff magnitude. Running the HEC- HMS for two events, using Snyder method resulted in exact values of peak runoff. However, the results of introduced model in this research showed that modelling based on physical relation and balance equation could simply estimate the value of peak flow exactly.

\section{Author's Contributions}

Maryam Ghashghaie, Saeid Eslamian, Kaveh Ostad-Ali-Askari and Ali Hasantabar Amiri: Designed the study, collected data, wrote the manuscript and revised it.

\section{Ethics}

All authors have met Ethics. This manuscript has not been published in other journals.

\section{References}

Aboelata, M., 1998. Object-Oriented modelling framework for water resources policy analysis. MSc Thesis, Department of Civil and Geological Engineering, University of Manitoba, Canada.

Ahmad, S. and S.P. Simonovic, 2004. Spatial system dynamics: New approach for simulation of water resources systems. J. Comput. Civil Eng., 18: 331-340. DOI: 10.1061/(ASCE)0887-3801(2004)18:4(331)

Ahmad, S. and S.P. Simonovic, 2006. An intelligent decision support system for management of floods. Water Resources Manage., 20: 391-410. DOI: $10.1007 / \mathrm{s} 11269-006-0326-3$

Anderson, M.L., Z.Q. Chen, M.L. Kavvas and A. Feldman, 2002. Coupling HEC-HMS with atmospheric models for prediction of watershed runoff. J. Hydrol. Eng., 7: 312-318. DOI: 10.1061/(ASCE)1084-0699(2002)7:4(312)

Arabi, M., J.R. Frankenberger, B.A. Engel and J.G. Arnold, 2008. Representation of agricultural conservation practices with SWAT. Hydrol. Processes, 22: 3042-3055. DOI: 10.1002/hyp.6890

Belkhouche, B., I. Demtchouk and J. Steinberg, 1999. Design of object-oriented water quality software system. J. Water Resources Plann. Manage., 125: 289-296. DOI: 10.1061/(ASCE)0733-9496(1999)125:5(289)

Burger, C.M., O. Kolditz, H.J. Fowler and S. Blenkinsop, 2007. Future climate scenarios and rainfall-runoff modelling in the upper Gallego catchment (Spain). Environ. Pollut., 148: 842-854. DOI: 10.1016/j.envpol.2007.02.002

Cantor, M., 1998. Object-Oriented Project Management with UML. 1st Edn., John Wiley and Sons, Inc., New York, ISBN: 0471253030, pp: 368.

Cohen, S. and T. Neale, 2006. Participatory integrated assessment of water management and climate change in the Okanagan Basin. British Columbia, Final report, Environment Canada and University of British Columbia, Canada.

Connor, J., L. Cartwright and K. Stephenson, 2004. Collaborative water supply Planning: A shared vision approach for the Rappahannock Basin in Virginia. Proceedings of the World Water and Environmental Resources Congress, Jun. 27-Jul 1, Salt Lake City, Utah, United States.

Elshorbagy, A. and L. Ormsbee, 2006. Object-oriented modeling approach to surface water quality management. J. Environ. Modell. Software, 21: 689-698. DOI: 10.1016/j.envsoft.2005.02.001 
Gastelum Perez, J.R., 2006. Analysis of water resources alternatives to improve water allocation on the Conchos Basin during drought situations. $\mathrm{PhD}$ Thesis. University of Arizona. USA.

Gosain, A.K. and S. Rao, 2004. GIS-based technologies for watershed management. Curr. Sci., 87: 948-953.

Ichikawa, Y., Y. Tachikawa and K. Takara, 2000. Object oriented hydrological modeling System. Disaster Prevention Research Institute, Kyoto University, Japan.

Im, S., K. Brannan, S. Mostaghimi and J. Cho, 2003. A comparison of SWAT and HSPF models for simulating hydrologic and water quality responses from an urbanizing watershed. The Society for Engineering in Agricultural, Food and Biological System. An ASAE Meeting Presentation, Las Vegas, Nevada, USA.

Jang, S., M. Cho, J. Yoon, Y. Yoon and S. Kim et al., 2007. Using SWMM as a tool for hydrologic impact assessment. Desalination, 212: 344-356.

DOI: 10.1016/j.desal.2007.05.005

Johnson, M.S., W. F. Coon, V. K. Mehta, T.S. Steenhuis and E.S. Brooks et al., 2003. Application of two hydrologic models with different runoff mechanisms to a hillslope dominated watershed in the northeastern US: A comparison of HSPF and SMR. J. Hydrol., 284: 57-76.

DOI: 10.1016/j.jhydrol.2003.07.005

Kallin, L. and M.H. Hantush, 2006. Comparative assessment of two distributed watershed models with application to a small watershed. Hydrol. Processes, 20: 2285-2307. DOI: 10.1002/hyp.6063

Kalteh, A.M., 2007. Rainfall runoff modeling using Artificial Neural Network (ANNs). Department of Water Resources Engineering Lund Institute of Technology, Lund University, Sweden.

Kiker, G.A. and D.J. Clark, 2001. The development of a java based, object oriented modeling system for simulation of southern African hydrology. The Society for Engineering in Agricultural, food and Biological Systems. Sacramento Convention Center Sacramento, California, USA.

Martinez, C.J., K.L. Campbell and M.D. Annable, 2008. An object-oriented hydrologic model for humid, shallow water-table environments. J. Hydrol., 351: 368-381. DOI: 10.1016/j.jhydrol.2008.01.002

Minns, A.W. and M.J. Hall, 1996. Artificial neural networks as rainfall-runoff models. Hydrol. Sci., 41: 399-417. DOI: 10.1080/02626669609491511

Moradkhani, H. and S. Sorooshian, 2009. General review of rainfall-runoff modeling: Model calibration, data assimilation and uncertainty analysis. Hydrol. Modell. Water Cycle, 63: 1-24. DOI: 10.1007/978-3-540-77843-1_1
Nandalal, K.D.W. and S.P. Simonovic, 2003. State of the art report on system analysis methods for resolution of conflicts in water resources management. Technical Documents in Hydrology. UNESCO. IHP. WWAP.

Nasr, A., M. Bruen, P. Jordan, R. Moles and G. Kiely et al., 2007. A comparison of SWAT, HSPF and SHETRAN/GOPC for modelling phosphorus export from three catchments in Ireland. Water Res., 41: 1065-1073. DOI: 10.1016/j.watres.2006.11.026

Pandey, A., V.M. Chowdary, B.C. Mal and M. Billib, 2008. Runoff and sediment yield modeling from a small agricultural watershed in India using the WEPP model. J. Hydrol., 348: 305-319. DOI: $10.1016 /$ j.jhydrol.2007.10.010

Raclot, D. and J. Albergel, 2006. Runoff and water erosion modelling using WEPP on a Mediterranean cultivated catchment. Phys. Chem. Earth, 31: 1038-1047. DOI: 10.1016/j.pce.2006.07.002

Rao, M.N., D.A. Waits and M.L. Neilsen, 2000. A GISbased modeling approach for implementation of sustainable farm management practices. Environ. Modell. Software, 15: 745-753.

DOI: $10.1016 / \mathrm{S} 1364-8152(00) 00032-3$

Rossman, L.A., 2008. Storm water management model user's manual. United States Environmental Protection Agency, Version 5.0.

Santhi, C., N. Kannan, J.G. Arnold and M.D. Luzio, 2008. Spatial calibration and temporal validation of flow for regional scale hydrologic modeling. J. Am. Water Resources Assoc., 44: 829-846. DOI: $10.1111 /$ j.1752-1688.2008.00207.x

Sarangi, A., C.A. Madramootoo, P. Enright, S.O. Prasher and R.M. Patel, 2005. Performance evaluation of ANN and geomorphology-based models for runoff and sediment yield prediction for a Canadian watershed. Curr. Sci., 89: 2022-2033.

Schuman, A.H., R. Funkl and G.A. Schultz, 2000. Application of a geographic information system for conceptual rainfall-runoff modeling. J. Hydrol., 240: 45-61.

DOI: $10.1016 / \mathrm{S} 0022-1694(00) 00312-7$

Simonovic, S.P., 2002a. Global water dynamics: Issues for the 21st century. Water Sci. Technol., 45: 53-64. http://wst.iwaponline.com/content/45/8/53

Simonovic, S.P., 2002b. World water dynamics: Global modeling of water resources. J. Environ. Manage., 66: 249-267. DOI: 10.1016/S0301-4797(02)90585-2

Simonovic, S.P. and V. Rajasekaram, 2004. Integrated analyses of Canada's water resources: A system dynamics approach. Canad. Water Resources J., 29: 223-250. DOI: 10.4296/cwrj223 
Sterman, J.D., 2000. Business Dynamics: Systems Thinking and Modeling for a Complex World. 1st Edn., McGraw-Hill, Boston, MA., ISBN-10: 0072311355, pp: 982.

Tisdale, T., 1996. Object-oriented analysis of south Florida hydrologic systems. J. Comput. Civil Eng.. 10: 318-326.

DOI: 10.1061/(ASCE)0887-3801(1996)10:4(318)

Tripathi, M.P., R.K. Panda and N.S. Raghuwanshi, 2003. Identification and prioritisation of critical subwatersheds for soil conservation management using the SWAT model. Biosyst. Eng., 85: 365-379. DOI: $10.1016 / \mathrm{S} 1537-5110(03) 00066-7$

USACE-HEC, 2000. Hydrologic modelling system HEC-HMS technical reference manual. US Army Corps of Engineers, Hydrologic Engineering Centre (HEC), Davis, USA.

USACE-HEC, 2008. Hydrologic modelling system HEC-HMS v3.2 user's manual. US Army Corps of Engineers, Hydrologic Engineering Center (HEC), Davis, USA.

Van den Belt, M., 2004. Mediated Modeling: A System Dynamics Approach to Environmental Consensus Building. 1st Edn., Island Press, Washington, USA, ISBN-10: 155963961X, pp: 339.
Verma, A.K., M.K. Jha and R.K. Mahana, 2010. Evaluation of HEC-HMS and WEPP for simulating watershed runoff using remote sensing and geographical information system. Paddy Water Environ., 8: 131-144.

DOI: $10.1007 / \mathrm{s} 10333-009-0192-8$

Wang, J., J. Hassett and T. Endreny, 2005. An object oriented approach to the description and simulation of watershed scale hydrologic processes. Comput. Geosci., 31: 425-435.

DOI: $10.1016 /$ j.cageo.2004.09.025

Winz, I. and G. Brierley, 2007. The use of system dynamics simulation in integrated water resources management. School of Geography, Geology and Environmental Science, University of Auckland, New Zealand.

Wurbs, R.A., 1994. Computer models for water resources planning and management. Texas A\&M University, Department of Civil Engineering, Environmental, Ocean and Water Resources Division, College Station, Texas. 